\title{
AVALIAÇÃO DO DESEMPENHO DE IMPREGNANTE INIBIDOR DE CORROSÃO APLICADO EM ESTRUTU- RAS DE CONCRETO ARMADO SOB A AÇÃO DE ÍONS CLORETO
}

\author{
SILVA, R. M \\ Escola Politécnica de Pernambuco \\ Universidade de Pernambuco \\ 50.720-001 - Recife, Brasil \\ raniellimelo.eng@hotmail.com
}

\author{
MONTEIRO, E. C. B. \\ Escola Politécnica de Pernambuco \\ Universidade de Pernambuco \\ 50.720-001 - Recife, Brasil \\ nana.monteiro@uol.com.br
}

Resumo Existem inúmeros problemas com estruturas de concreto armado, e um dos mais comuns e que apresenta maior risco é a corrosão de armaduras. Sabendo disso, torna-se importante a busca por meios de evitar a corrosão. Diante do exposto, esta pesquisa buscou avaliar a eficiência de um novo material de reparo, aplicado na superfície da estrutura de concreto, quando exposto aos agentes de corrosão. Foram feitos ensaios em pequenos corpos de prova simulando a ação desses agentes, tendo sempre como base outros corpos sem o uso do produto. Após a fase experimental notou-se uma eficiência abaixo do esperado do produto nos diferentes tipos de corpos de prova e com isso concluiu-se que o Inibidor de Corrosão não correspondeu ao esperado sendo pouco eficiente em ambientes marinhos agressivos como o da cidade do Recife.

\footnotetext{
Abstract There are numerous problems with reinforced concrete structures, and one of the most common and the most risky is the corrosion of steel bars. Knowing this, it becomes important to search for ways to prevent corrosion. Given the above, this study sought to evaluate the efficiency of a new repair material, applied to the surface of the concrete structure when exposed to corrosive agents. Tests were made on small specimens simulating the action of these agents, are always focused on other specimens without the use of the product. After the experimental phase we observed a lower than expected efficiency of the product in different types of specimens and thus concluded that the corrosion inhibitor did not correspond the expected being less efficient in harsh marine environments such as the city of Recife.
} 


\section{Introdução}

No Brasil, vários levantamentos já foram realizados sobre as manifestações patológicas nas estruturas de concreto. Aranha (1994) em um levantamento realizado na região Amazônica mostrou que $45 \%$ das obras foram atacadas por corrosão e recentemente Teixeira e Gonçalves (2003) inspecionaram 200 pontes no estado do Piauí e também foram constatados problemas diversos de corrosão de armadura. Em Pernambuco, Andrade (1997) encontrou resultados alarmantes dessas manifestações e concluiu que a corrosão de armaduras é o causador da maior parte dos danos nas estruturas de concreto, sendo responsável por mais de $50 \%$ das patologias registradas em edificações. A depassivação da armadura ocorre após a quebra da situação de equilíbrio que de inicio é apresentado no concreto. Este, por sua vez, tem uma elevada alcalinidade, com Ph acima de 12,6. Com o processo de carbonatação ou de penetração de íons cloreto, o concreto passa a ficar mais ácido, fazendo com que ocorra a corrosão. A fase de iniciação da corrosão depende da estimativa de vida útil de projeto da estrutura, (HELENE, 1993). Após depassivada a armadura, ocorre o processo de propagação por toda extensão, este processo é acelerado pela freqüente carbonatação e adição de cloretos (ALONSO \& ANDRADE, 1988, MONTEIRO, 1996).

A durabilidade consiste na capacidade da estrutura resistir às influências ambientais previstas e definidas em conjunto pelo autor do projeto estrutural (ABNT, 2003). O grande problema em relação à durabilidade é o envelhecimento da estrutura, porém isso vem ocorrendo cada vez mais cedo. Estudos comprovam que em países mais pobres os custos com recuperação chegam a 70\% dos custos aplicados, pois não há medidas de prevenção, enquanto nos países mais desenvolvidos os custos não passam de 3,5\% do produto interno bruto (ARANHA, 1994, ANDRADE \& GONZALES, 1978).

Vida útil é aquela durante a qual a estrutura conserva todas as características mínimas de funcionabilidade (ANDRADE, 1992). Um estudo realizado por Tuutti (1982) propôs um modelo teórico de vida útil aplicada à corrosão de armaduras, a Figura 1 é a representação esquemática do seu modelo.

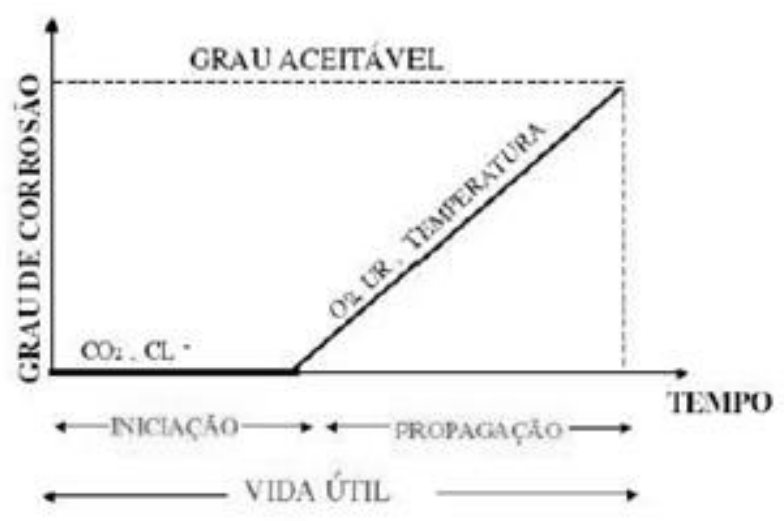

\section{Fig 1. Modelo de Vida Util proposto por Tuutti}

No período de INICIAÇÃO, o dióxido de carbono e os íons cloreto penetram desde o interior e avançam até a armadura. Helene (1993) considera que a duração da fase de iniciação deve corresponder à estimativa da vida útil de projeto da estrutura quanto à corrosão.

A itensificação do processo de corrosão acontece no período de PROPAGAÇÃO.

A relação água/cimento é um dos fatores mais importantes, ela influencia na porosidade e consequentemente na penetração dos íons cloreto na estrutura (MONTEIRO, 2002). Monteiro (1996), pesquisando três tipos de cimentos nacionais, verificou que a redução da relação água/cimento melhorou o desempenho dos cimentos em relação à corrosão de armaduras por íons cloreto, aumentando significativamente a sua fase de iniciação.

Segundo Holden (1986, apud MONTEIRO, 2002) a composição química do cimento tem grande influência na penetração de íons cloreto, já que o silicato tricálcico (C3A) e o ferro aluminato de cálcio (C4AF) se combinam com os íons cloreto para formar os cloroaluminatos. Essa reação diminui o fluxo de penetração de íons cloreto devido à redução da concentração de íons livres na solução aquosa dos poros do concreto.

Collepardi; Marcialis; Turriziani (1972) verificaram que os concretos mais bem compactados têm o coeficiente de difusão de íons cloreto inferiores àqueles não compactados.

Elevadas temperaturas aumentam a velocidade de penetração dos íons cloretos e as fissuras que existem nas estruturas facilitam o caminho dos agentes corrosivos.

A absorção capilar também é um dos fatores que ditam a corrosão, já que o ingresso da água depende da densidade dos poros do concreto. $\mathrm{O}$ fenômeno de absorção não acontece em concretos saturados, pois o concreto deve estar com os poros secos ou parcialmente secos para que seja possível a absorção de água por capilaridade (HELENE, 
1993).

Outro fator é a permeabilidade que consiste na facilidade com que um fluido possa penetrar num sólido (MEHTA; MONTEIRO, 1994). Esta situação ocorre tanto em estruturas submersas quanto em parcialmente submersas e podem acelerar a penetração dos agentes.

\section{Metodologia}

Para minimizar a penetração dos agentes corrosivos no concreto armado, foi utilizado um material impregnante aquoso que tem como função proteger o concreto dos efeitos da corrosão e aumentar a durabilidade do concreto.

Para avaliar a eficiência desse material foi usado cimento do tipo CP II Z-32, por ser o mais utilizado no estado de Pernambuco, areia oriunda da própria região passada pelo ensaio de granulometria de acordo com a NBR 7217 (ABNT, 1987) e aço CA-60 com diâmetro de 5,0mm, obtido por trefilação de fio máquina e produzidos segundo as especificações da NBR 7480 (ABNT, 1985).

\section{Séries de Ensaios}

Com o objetivo de avaliar o comportamento em diferentes condições micro-estruturais, foram utilizadas duas variações da relação a/c: 0,4 e a 0,7. Já que a relação água/cimento é o principal parâmetro que influencia diretamente na porosidade (MEHTA, 1994).

Neste programa experimental foram utilizadas duas séries para cada tipo ensaio: A Série R e a Série A. A série "R" corresponde à série referência, ou seja, sem aplicação de material algum de reparo, já a Série "A" corresponde à série na qual será aplicada a pintura superficial.

\section{Descrição dos corpos de Prova}

Para os ensaios acelerados de corrosão foram confeccionados corpos de prova com dimensões $60 \times 25 \times 80$ $(\mathrm{mm})$, armados com duas barras de aço longitudinais de diâmetro $5,0 \mathrm{~mm}$ com cobrimento definido. As barras foram dimensionadas com um comprimento maior, de modo a ficar com a sua extremidade exposta para possibilitar a conexão elétrica das armaduras para monitoramento da corrosão.

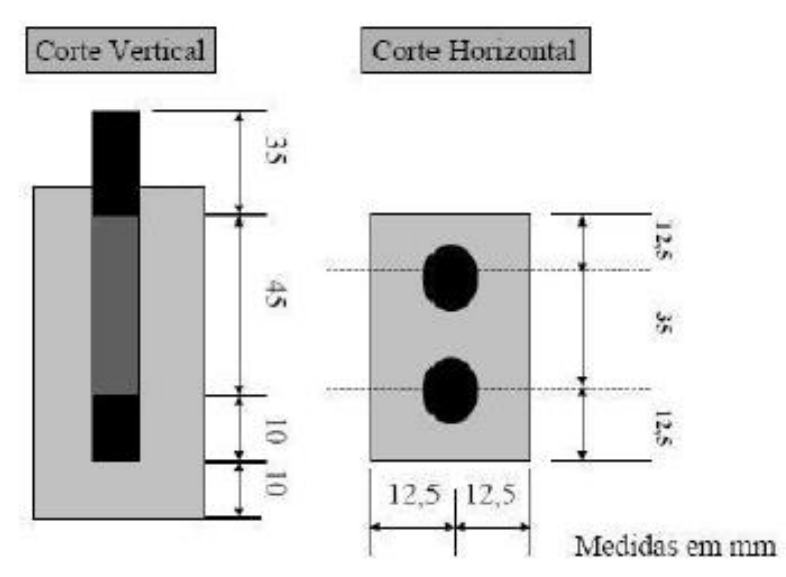

Fig 2. Dimensionamento dos Corpos de prova

\section{Preparo e Limpeza das Barras}

As armaduras utilizadas nos corpos de prova sofreram um procedimento de limpeza específico, já que foram utilizadas como sensores de corrosão nos ensaios acelerados de corrosão. O procedimento de limpeza empregado se baseia na norma ASTM C - 1152/ (1992).

\section{Modelagem}

A moldagem dos corpos de prova dos ensaios acelerados foi planejada para se ter o maior grau possível de homogeneidade e principalmente precisão de forma, dimensões e posicionamento da barra. $\mathrm{O}$ procedimento de moldagem foi feito de forma manual, numa fôrma de plástico e teve o lançamento e o adensamento em duas camadas. Foi utilizado um soquete no adensamento das camadas.

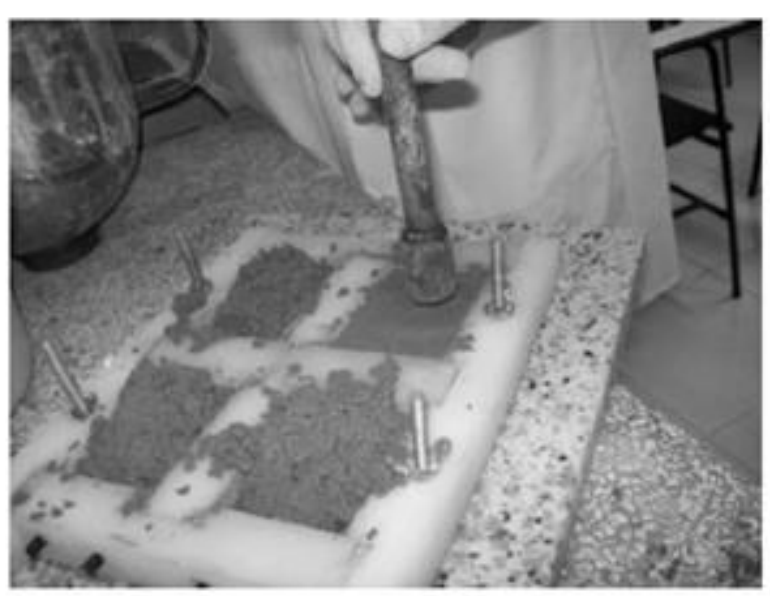

Fig 3.Moldagem dos corpos prismáticos 


\section{Cura}

Logo após o procedimento de moldagem, os corpos de prova foram colocados em câmara úmida e desmoldados após 24 horas mantendo - os em cura até a idade determinada.

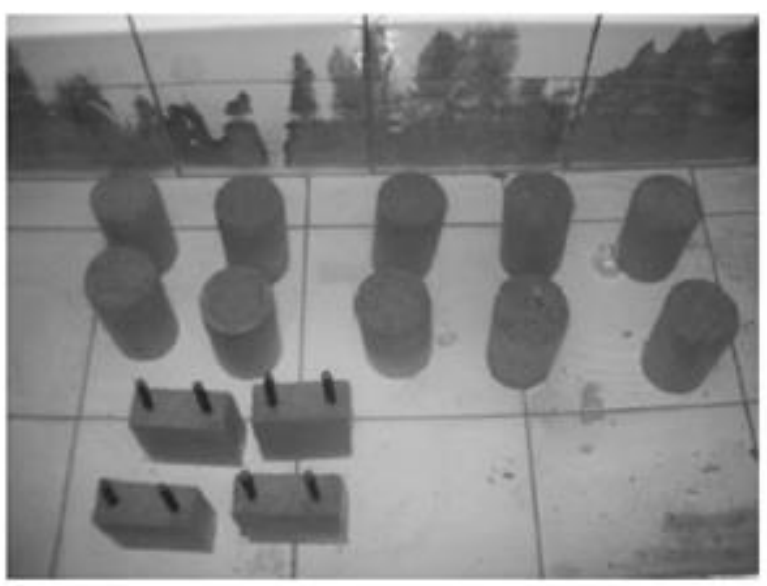

FIg 4. Corpos de prova em Cura

Após a cura foi aplicado, com o uso de pinceis e dentro das normas de segurança, utilizando bata, luvas e máscaras, o material de reparo nos corpos de prova.

\section{Ensaios Acelerados de Penetração de Íons Clore- tos}

Como o mecanismo de ingresso de cloretos varia de acordo com o tipo de ensaio e das condições de umidade, desta maneira foi escolhida a condição de imersão parcial em $\mathrm{NaCl}$ com semi-ciclos de secagem e umectação de acordo que as metodologias que envolvem ciclos de secagem e imersão parcial ou contato com solução de $\mathrm{NaCl}$ correspondem ao regime mais severo de penetração de cloretos (PAGE at all,1991).

Tabela 1. Tabela de semi-ciclo

\begin{tabular}{|l|l|l|}
\hline SEMICICLO & CONDIÇĀOO & DURAÇAO \\
\hline Secagem & Estufa & 5 dias \\
\hline Imersão Parcial & Parcialmente Submerso & 2 dias \\
\hline
\end{tabular}

No ciclo de secagem os corpos ficam em estufa a $50^{\circ} \mathrm{C}$. No ciclo de umectação, os corpos ficam submersos até metade de sua altura da área de exposição das barras. Deste modo, se tem à absorção por capilaridade e a medição das variáveis estudadas se dá a cada fím de semi-ciclo.

Também foram realizados ensaios complementares: Absorção por imersão e por capilaridade, pois considerase que a penetração de água tem dois efeitos de grande importância na durabilidade de uma estrutura de concreto.

\section{Absorção por Imersão}

Neste ensaio foram utilizados corpos de prova cilíndricos com 5,0 cm de diâmetro e 10,0 cm de altura, o procedimento a ser adotado consta na NBR 9798 (ABNT, 1987) o produto avaliado foi aplicado em todas as faces. Após este procedimento os corpos de prova foram mantidos em ambiente de laboratório por mais de 7 dias para assegurar a cura dos sistemas de proteção. Foram empregados 04 corpos de prova para cada material estudado.

A absorção foi medida através da pesagem dos corpos de prova após a secagem superficial dos mesmos.

\section{Absorção por Capilaridade}

Este ensaio foi conduzido de acordo com as recomendações com a NBR 9779 (ABNT, 1995), utilizando corpos de prova cilíndricos de diâmetro 5,0 cm x 10 cm de comprimento.

Os corpos foram tratados da mesma forma que os utilizados no ensaio de Imersão.

Foi aplicada uma proteção com silicone até a altura de $4 \mathrm{~cm}$ a partir da face onde o sistema de proteção superficial será aplicado. Este cuidado foi tomado para induzir que a penetração de água só ocorra por uma das faces circulares do corpo-de-prova. O nível de água foi mantido constante e igual a $5 \mathrm{~mm}$ durante todo o ensaio.

O monitoramento da absorção de água foi acompanhado a partir de pesagem dos corpos de prova ao longo do período de experimento.

O acompanhamento das variações de massa dos corpos de prova de ambos os ensaios foram realizados até os 30 dias após o primeiro contato a água. 


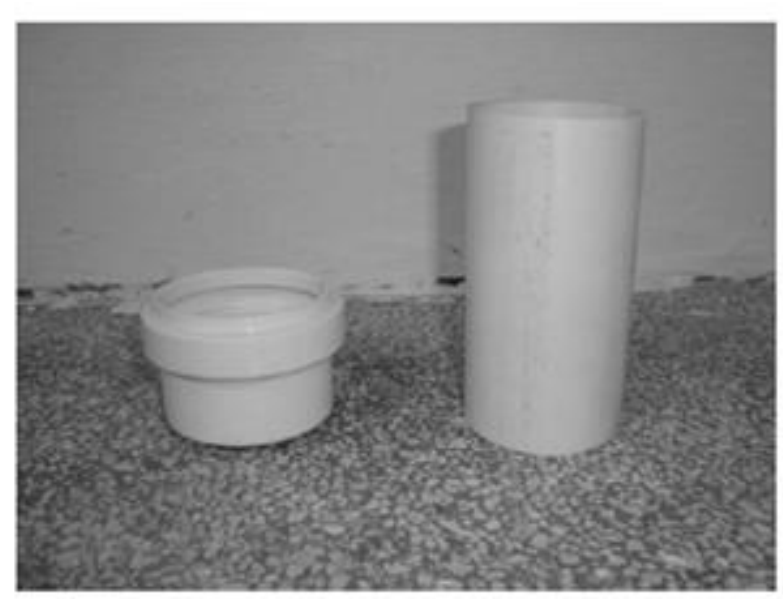

Fig 5. Fôrma de plástico para melhor desmoldagem.

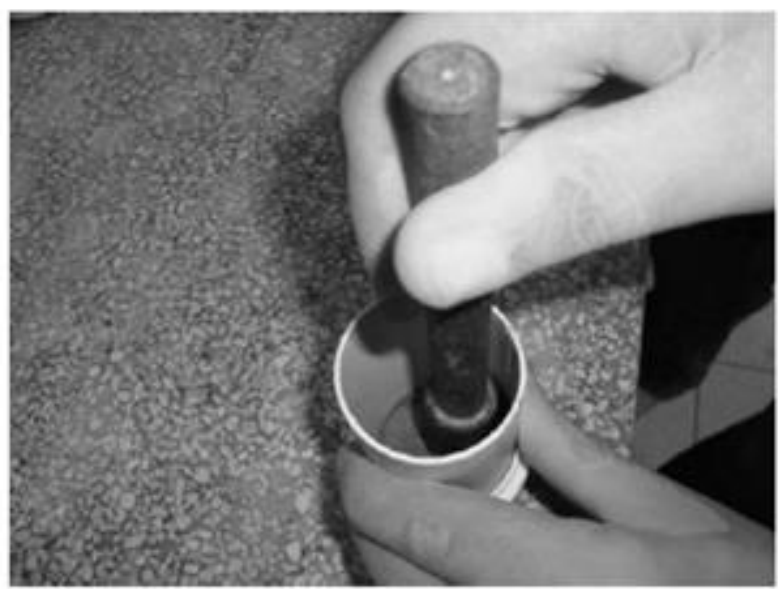

Fig 6. Soquete utilizado para o adensamento das camadas

\section{Ensaios Eletroquímicos: Medida de Potencial de Corrosão}

O Potencial de corrosão (Ecorr) pode ser considerado um indicador de deterioração. A norma ASTM C - 876/ (1992) associa uma probabilidade superior a $95 \%$ de corrosão para valores de potenciais inferiores a $-350 \mathrm{mV}$, para eletrodo de cobre/sulfato de cobre.

Neste ensaio foram utilizados os equipamentos enumerados abaixo:

\section{Multímetro}

2. Eletrodo de cobre/ sulfato de cobre saturado para as leituras de potencial de corrosão.

\section{Resultados e Discussões}

\section{Absorção de água \\ Absorção de água por imersão}

Os resultados da Figura 7 abaixo indicam que na relação água/cimento 0,4 os corpos de prova com aplicação do Impregnante inibidor de corrosão tiveram uma menor penetração de água em sua estrutura em relação aos corpos de prova de referência.



Fig 7. Absorção por Imersão $(0,4)$

A Figura 8 refere-se à relação a/c 0,7 , que pelo gráfico nota-se uma penetração de água maior que a da relação 0,4 . $\mathrm{O}$ que demonstra uma menor eficiência do Impregnante nesta condição, já que o ingresso de água no concreto é o principal fator para que ocorra a corrosão. Pode-se observar também que não houve significativa variação na penetração de água nos corpos de prova com impregnante e de referência.

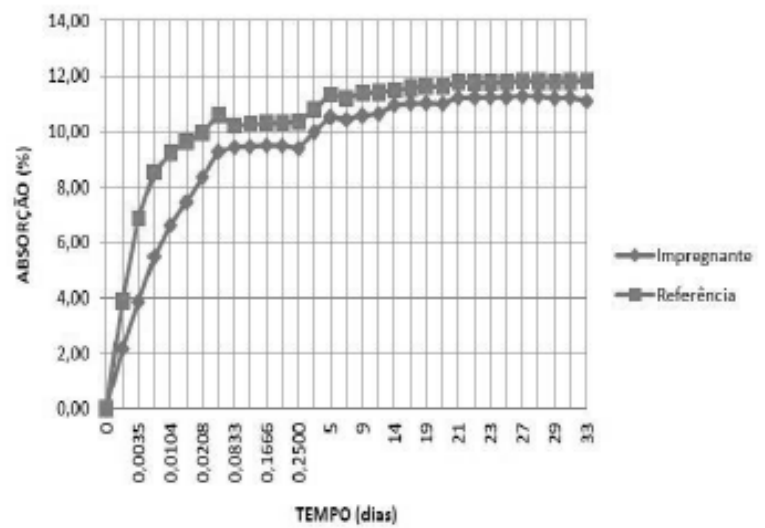

Fig 8. Absorção por Imersão $(0,7)$ 


\section{Absorção de água por capilaridade}

No gráfico referente à relação a/c 0,4 , é visto que a diferença obtida entre os corpos referência e os corpos com a aplicação do Impregnante é insignificante (Figura 09).

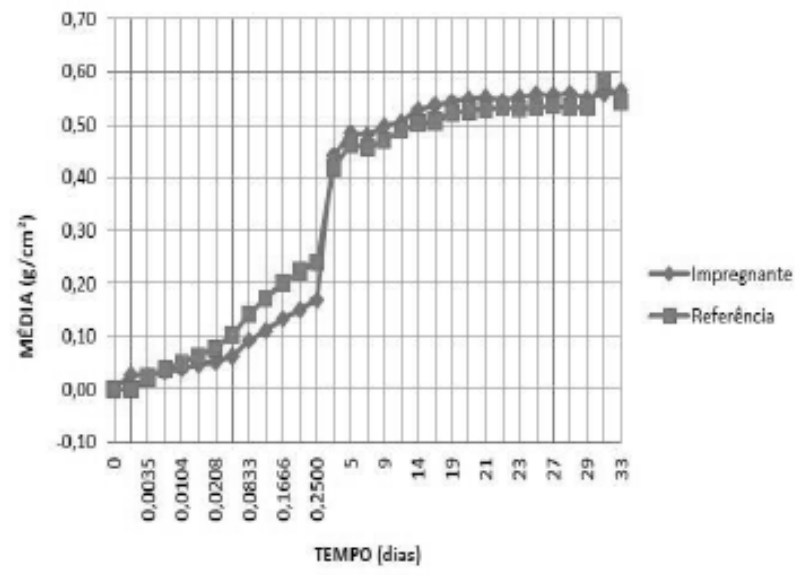

Fig 9. Absorção por Capilaridade $(0,4)$

Já no gráfico referente aos corpos de prova com relação água/cimento 0,7 percebe-se uma diminuição significativa na absorção de água com a utilização do Impregnante Inibidor de Corrosão (Figura 10).

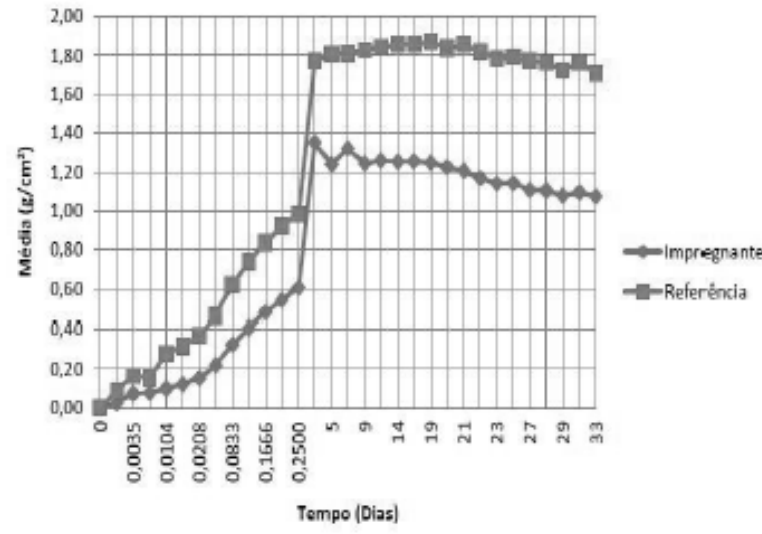

Fig 10. Absorção por Capilaridade $(0,7)$

\section{Evolução do Potencial de Corrosão (Ecoor)}

Os resultados de corrosão nos corpos de prova com relação a/c 0,4 e os resultados nos corpos de prova com relação 0,7 obtidos nos gráficos abaixo (Figuras 11 e 12), mostram que após 42 dias de ciclagem, não se obteve melhorias expressivas com a utilização do Impregnante nos corpos de prova. Tendo em vista que ambos os corpos, tanto os de referência quanto os com o produto, estiveram abaixo do patamar de $-350 \mathrm{mV}$ em relação ao eletrodo de cobre / sulfato de cobre, indicando que em todos os casos, a barra esteve com alta probabilidade de corroer.

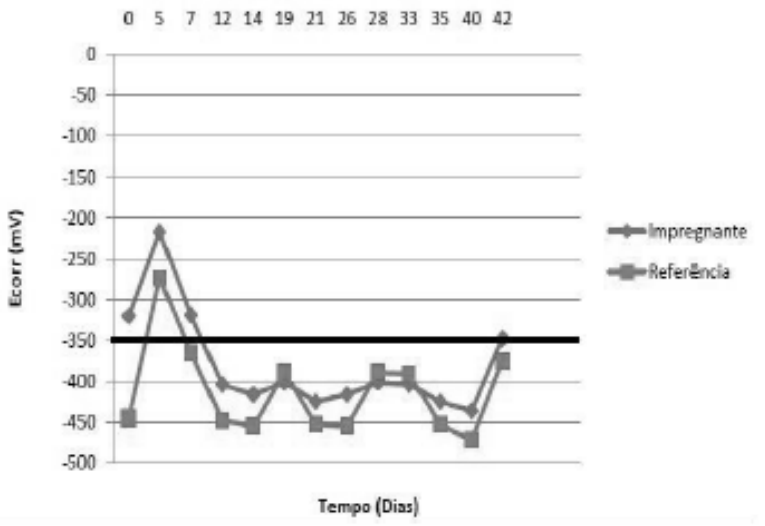

Fig 11. Potencial de corrosão $(0,4)$

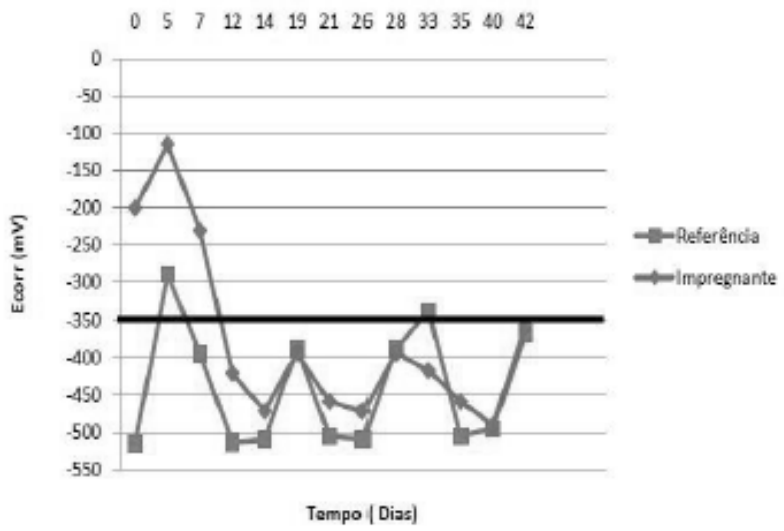

Fig 12. Potencial de corrosão $(0,7)$

\section{Conclusões}

Com base nos dados obtidos nesta pesquisa foi possível analisar a eficácia do Impregnante Inibidor de corrosão, através de gráficos comparativos.

Com relação à absorção de água por Imersão ficou claro a pouca eficiência do produto em ambas as relações água/cimento, já que o mesmo não impediu de forma significativa o ingresso de água na estrutura.

$\mathrm{Na}$ absorção de água por capilaridade o produto se mostrou mais eficiente quando aplicado nos corpos de prova com relação água/cimento 0,7 . Quando aplicado nos corpos com relação água/cimento 0,4 o produto não mostrou nenhuma melhora. 
Analisando o Potencial de corrosão foi visto que em ambas as relações água/cimento os corpos de prova cruzaram o patamar de $-350 \mathrm{mV}$ nas primeiras semanas de ciclagem, o que mostra a baixa interferência do Impregnante no aspecto preventivo da corrosão.

Tendo em vista as informações acima se conclui que o produto Impregnante Inibidor de Corrosão não correspondeu ao esperado, sendo pouco eficiente em ambientes marinhos agressivos como o da cidade do Recife.

\section{Agradecimentos}

Agradeço ao NPEC - Núcleo de Pesquisa em Engenharia Civil - que me ajudou e proporcionou o espaço físico para a realização de pesquisas, a todos meus orientadores, diretos e indiretos, ao Grupo RECUPERAR e ao PIBIC POLI - Programa Institucional de Base de Iniciação Científica - da Escola Politécnica de Pernambuco/Universidade de Pernambuco pelo apoio financeiro ao desenvolvimento de minha pesquisa.

\section{Referências}

[1] AMERICAN SOCIETY FOR TESTING AND MATERIALS. Standard test method for acid-soluble cloride in mortar and concrete. ASTM C 1152: 1992. Philadelphia: Annual Book of ASTM Standards.

[2] ASSOCIAÇÃO BRASILEIRA DE NORMAS TÉCNICAS - Projeto de estruturas de concreto Procedimento -. Rio de Janeiro. NBR 6118. 2003.

[3] determinação da absorção de água por capilaridade - NBR 9779: Rio de Janeiro. 1995.

Barras e fio de Aço destinados a armadura para concreto armado - NBR 7480: Rio de Janeiro. 1985.

[5] . Determinação da composição granulométrica - NBR 7217: Rio de Janeiro. 1987. Determinação da resistência à compressão - NBR 7215: Rio de Janeiro. 1996.

[7] ARANHA, P.M.S. Contribuição ao estudo das manifestações patológicas em estruturas de concreto armado na região amazônica. Dissertação (Mestrado). Universidade Federal do Rio Grande do Sul, 1994.

[8] ANDRADE, C.; GONZÁLEZ, J. A. Quantitative measurements of corrosion rate of reinforcing steels embedded in concrete using polarization re- sistence measurements. Werkstoffe um Korrosion, Berlim, Alemanha, v. 29, p. 515-19, 1978

[9] ANDRADE, C. Manual de Diagnósticos de Obras Deterioradas por Corrosão de Armaduras. Editora Pini, São Paulo, 1992.104p.

[10] ALONSO, M. C.; ANDRADE, C. Corrosion of steel reinforcement in carbonated mortar containing chloride. Advanced Cement Research, v.1, p. 155-163, 1988.

[11] COLLEPARDI, M.; MARCIALIS, A; TURRIZIANI, R. Penetration of Chloride Ions into Cement Pastes and Concretes. Journal of the American Ceramic Society, v.55, n.10, p.533-535. 1972.

[12] HELENE, P.R.L. Contribuição ao estudo da corrosão em armaduras de concreto armado. 1993. 231p e 271f. Tese (Livre-Docência) - Escola Politécnica, Universidade de São Paulo. São Paulo.

[13] MEHTA. P.K.; MONTEIRO, P.J.M. Concreto: Estrutura, propriedades e materiais. 2. ed. São Paulo: Ed. Pini, 1994. 573p.

[14] MONTEIRO, E.C.B. Estudo da capacidade de proteção de alguns tipos de cimentos nacionais, em relação à corrosão de armaduras, sob a ação conjunta de CO2 e íons cloretos. 1996. 138p. Dissertação (Mestrado) - Departamento de Engenharia Civil, Universidade de Brasília. Brasília

[15] MONTEIRO, E.C.B. Avaliação do método de extração eletroquimica de cloretos para reabilitação de estruturas de concreto com problemas de corrosão de armaduras. 2002. p.211 Tese (Doutorado) - Escola Politecnica, Universidade de São Paulo, São Paulo.

[16] PAGE, C.L.; SHORT, N.R.; HOLDEN, W.R. The influence of different cements on choloride induced corrosion of reinforcing steel. Cement and Concrete Research, v.16, n.5, p.79-86, September. 1986.

[17] PAGE, C.L.; LAMBERT, P. \& VASSIE, P.R. Investigations of reinforcement corrosion. 1. The pore electrolyte phase in chloride-contaminated concrete. Materials and Structures, 1991. Vol. 24, pp. 243-252.

[18] TEIXEIRA, P. W. G. N.; GONSALVES, F. D. R. Avaliação geral do estado de conservação de pontes existentes nas rodovias piauienses. In: Simpósio EPUSP sobre Estruturas de Concreto, 5, 2003, São Paulo. Anais. São Paulo: 2003.

[19] TUUTTI, K. Corrosion Stell in Concrete. Stockolm: Cement and Concrete Research Institute, 
Stockolm, 1982, 469p. 